\title{
Analyst
}

CORRECTION

(a)

CrossMark

Cite this: Analyst, 2016, 141, 6604

DOI: 10.1039/c6an90098d

www.rsc.org/analyst
View Article Online

View Journal | View Issue

\section{Correction: In solution SERS sensing using mesoporous silica-coated gold nanorods}

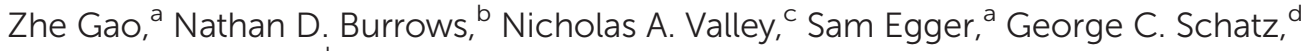
Catherine J. Murphy ${ }^{b}$ and Christy L. Haynes ${ }^{* a}$

Correction for 'In solution SERS sensing using mesoporous silica-coated gold nanorods' by Zhe Gao, et al., Analyst, 2016, 141, 5088-5095.

The authors regret the omission of one of the authors, Sam Egger, from the original manuscript. The corrected list of authors and affiliations for this paper is as shown above. The statement in the Acknowledgements section that refers to Sam Egger should be disregarded.

The Royal Society of Chemistry apologises for these errors and any consequent inconvenience to authors and readers.

\footnotetext{
${ }^{a}$ Department of Chemistry, University of Minnesota 207 Pleasant St SE, Minneapolis, MN 55455, USA. E-mail: chaynes@umn.edu

${ }^{b}$ Department of Chemistry, University of Illinois at Urbana-Champaign, 600 S Mathews Ave, Urbana, IL 61801, USA

${ }^{c}$ College of Health Sciences, California Northstate University 2910 Prospect Park Drive, Rancho Cordova, CA 95670, USA

${ }^{d}$ Department of Chemistry, Northwestern University 2145 Sheridan Rd, Evanston, IL 60208, USA
} 